\title{
Size-segregated characteristics of organic carbon (OC), elemental carbon (EC) and organic matter in particulate matter (PM) emitted from different types of ships in China
}

\author{
Fan Zhang ${ }^{1,2}$, Hai Guo ${ }^{1}$, Yingjun Chen ${ }^{2,3,4}$, Volker Matthias ${ }^{5}$, Yan Zhang ${ }^{2}$, Xin Yang ${ }^{2,4}$, and Jianmin Chen ${ }^{2}$ \\ ${ }^{1}$ Air Quality Studies, Department of Civil and Environmental Engineering, The Hong Kong Polytechnic University, \\ Hong Kong SAR, China \\ ${ }^{2}$ Shanghai Key Laboratory of Atmospheric Particle Pollution and Prevention (LAP3), Department of Environmental Science \\ and Engineering, Fudan University, Shanghai 200092, China \\ ${ }^{3}$ Key Laboratory of Pollution Control and Resource Reuse, College of Environmental Science and Engineering, \\ Tongji University, Shanghai 200092, China \\ ${ }^{4}$ Shanghai Institute of Pollution Control and Ecological Security, Shanghai 200092, China \\ ${ }^{5}$ Institute of Coastal Research, Helmholtz-Zentrum Geesthacht, Max-Planck-Straße 1, 21502 Geesthacht, Germany
}

Correspondence: Hai Guo (hai.guo@polyu.edu.hk) and Yingjun Chen (yjchenfd@fudan.edu.cn)

Received: 16 April 2019 - Discussion started: 9 July 2019

Revised: 20 November 2019 - Accepted: 11 December 2019 - Published: 7 February 2020

\begin{abstract}
Studies of detailed chemical compositions in particles with different size ranges emitted from ships are in serious shortage. In this study, size-segregated distributions and characteristics of particle mass, organic carbon (OC), elemental carbon (EC), 16 EPA polycyclic aromatic hydrocarbons (PAHs) and $25 n$-alkanes measured aboard 12 different vessels in China are presented. The results showed the following. (1) More than half of the total particle mass, OC, EC, PAHs and $n$-alkanes were concentrated in fine particles with aerodynamic diameter $\left(D_{p}\right)<1.1 \mu \mathrm{m}$ for most of the tested ships. The relative contributions of OC, EC, PAH and alkanes to the size-segregated particle mass are decreasing with the increase in particle size. However, different types of ships showed quite different particle-size-dependent chemical compositions. (2) In fine particles, the OC and EC were the dominant components, while in coarse particles, OC and EC only accounted for very small proportions. With the increase in particle size, the OC /EC ratios first decreased and then increased, having the lowest values for particle sizes between 0.43 and $1.1 \mu \mathrm{m}$. (3) Out of the four OC fragments and three EC fragments obtained in thermal-optical analysis, OC1, OC2 and OC 3 were the dominant OC fragments for all the tested ships, while EC1 and EC2 were the main EC fragments for ships running on heavy fuel oil (HFO) and
\end{abstract}

marine-diesel fuel, respectively; different $\mathrm{OC}$ and EC fragments presented different distributions in different particle sizes. (4) The four-stroke low-power diesel fishing boat (4LDF) had much higher PAH emission ratios than the fourstroke high-power marine-diesel vessel (4-HMV) and twostroke high-power heavy-fuel-oil vessel (2-HHV) in fine particles, and 2-HHV had the lowest values. (5) PAHs and $n$ alkanes showed different profile patterns for different types of ships and also between different particle-size bins, which meant that the particle size should be considered when source apportionment is conducted. It is also noteworthy from the results in this study that the smaller the particle size, the more toxic the particle was, especially for the fishing boats in China.

\section{Introduction}

Particulate matter (PM) emitted from ships has significant impacts on human health and air quality (Schröder et al., 2017; Liu et al., 2016; Oeder et al., 2015; Viana et al., 2014). Ship emission is one of the most important sources of fine particulate matter $\left(\mathrm{PM}_{2.5}\right)$ in harbor or offshore areas. PM from both heavy-fuel-oil and marine-diesel fuel ship- 
ping emissions shows strong biological effects on human lung cells (Oeder et al., 2015). A previous study indicated that shipping emissions in eastern Asia lead to 8700-25 500 premature deaths per year due to $\mathrm{PM}_{2.5}$ (Liu et al., 2016). PM emitted from ships in harbor cities or areas accounts for non-ignorable proportions of primary $\mathrm{PM}_{2.5}$ (Gregoris et al., 2016; Zhao et al., 2013; Agrawal et al., 2009). This fraction can reach up to $17 \%-30 \%$ if the contribution of shipping emissions to secondary particles is considered, too (Pandolfi et al., 2011; Liu et al., 2017). The chemical composition of $\mathrm{PM}$ emitted from ships is complex. Organic matter (OM), elemental carbon (EC) or black carbon (BC), water-soluble ions, and heavy metals are the main components. In addition, polycyclic aromatic hydrocarbons (PAHs) in PM emitted from ships have drawn much attention due to their significantly negative impact on human health as well as their diagnostic characteristics for source apportionment (Vieira de Souza and Corrêa, 2015; Pongpiachan et al., 2015; Alves et al., 2015). Ships are considered to be one of the most important sources for BC emissions in Arctic areas (Schröder et al., 2017; Quinn et al., 2011; Corbett et al., 2010) that could lead to the increase in ice melt due to its strong light-absorbing properties. BC-containing aerosols in the Arctic can perturb the radiation balance with either a warming effect or a cooling effect on climate depending on the albedo of the underlying surface relative to the albedo of the BC haze itself (Quinn et al., 2011). Besides this, as a key component of soot, BC is also considered to have substantial negative consequences for health. Furthermore, as important components, water-soluble ions such as $\mathrm{SO}_{4}^{2-}, \mathrm{NO}_{3}^{-}, \mathrm{NH}_{4}^{+}, \mathrm{Cl}^{-}$and $\mathrm{Na}^{+}$are routinely studied due to their unique emission characteristics in PM of ships, different from other sources (Sippula et al., 2014; Moldanová et al., 2013, 2009; Agrawal et al., 2008). Notably, heavy metals generally have high levels in PM emitted from ships compared to other sources. This especially holds for HFO-fueled (heavy-fuel-oil-fueled) ships, where metals like vanadium can be used as tracers (Moldanová et al., 2009; Agrawal et al., 2009). In addition, because a large number of particles emitted from ships are very small $(<0.1 \mu \mathrm{m})$, which may have significant impacts on cloud formation (Fridell et al., 2008), particle number concentrations, particularly for ultrafine particles, have gained more and more attention in recent years.

The size-resolved number and mass distributions of particles emitted from ship engines have been investigated for more than 1 decade due to their potential climate impacts and influence on human health. Three measurement methods, including engine tests, onboard tests and plume tracking, are usually reported in the literature. However, most of the previous studies focused on the size-resolved particle number distributions (Wu et al., 2018; Cappa et al., 2014; Beecken et al., 2014; Moldanová et al., 2013; Juwono et al., 2013; Diesch et al., 2013; Alfoeldy et al., 2013; Winnes and Fridell, 2010; Kasper et al., 2007; Cooper, 2003), which reported that the total particle number concentrations were dominated by ultrafine particles (nucleation mode) or fine particles. For example, the mean particle diameter was between 25 and $40 \mathrm{~nm}$ for a two-stroke marine-diesel engine (Kasper et al., 2007) and between 40 and $60 \mathrm{~nm}$ for a fourstroke marine-diesel engine measured on a test bench (Petzold et al., 2008). Unimodal characteristics with the peak at $0.1 \mu \mathrm{m}$ (Sinha et al., 2003; Fridell et al., 2008), 40-50 nm (Chu-Van et al., 2017), 30-40 nm (Winnes and Fridell, 2010) or even $10 \mathrm{~nm}$ (Moldanová et al., 2013) were observed during onboard tests. Bimodal patterns were found in plumes with maxima at $10-20 \mathrm{~nm}$ and $100 \mathrm{~nm}$ (Petzold et al., 2008) and 10 and $35 \mathrm{~nm}$ (Diesch et al., 2013). Particles with a marked nucleation mode (10-100 nm; Hobbs et al., 2000; Healy et al., 2009) and 58-131 nm (Juwono et al., 2013) were also found in the plumes from different marine fuel oil commercial ships and berthing bulk and container ships. It should be noted that the engine type and operating mode could affect the particle number distribution (Juwono et al., 2013; Cappa et al., 2014).

Few studies involved size-resolved particle mass distributions emitted from ships (Chu-Van et al., 2017; Moldanová et al., 2013, 2009; Murphy et al., 2009; Fridell et al., 2008). Although most of the particles from ships were concentrated in the nucleation mode in terms of number concentration, the particle mass was dominated by particles in the accumulation mode or even coarse mode. For example, it was found that the mass distribution of hot-exhaust particles from a largeship diesel engine had two main peaks: one in the accumulation mode at a $D_{p}$ around $0.5 \mu \mathrm{m}$ and the other in the coarse mode at a $D_{p}$ around $7 \mu \mathrm{m}$ (Moldanová et al., 2009). Another earlier study also found that particles with a diameter of approximately $8 \mu \mathrm{m}$ presented the largest mass peak in the mass spectrum for three tested ships (Fridell et al., 2008). The size-resolved mass distribution of particles has not been fully studied. One reason is that although the coarse particles account for non-ignorable proportions of the total mass, they are relatively few in the number concentration, which has not caught much attention. Moreover, particles with a size around $8 \mu \mathrm{m}$ are usually not detected by particle counters when the counting method is used to calculate the particle mass. Only one study collected particles from ships using an in-stack cascade impactor, which revealed different mass distribution patterns from the particle counting method (Cooper, 2003). The result indicated that, though the smaller particles $(<1 \mu \mathrm{m})$ were dominant in number concentration, they only accounted for $10 \%-50 \%$ of the total mass (Cooper, 2003). The counting method was simple but had drawbacks; namely, the mass could bias towards larger particles.

A handful of studies on detailed chemical compositions of particles in different sizes were conducted (Wu et al., 2018; Murphy et al., 2009). An aerosol mass spectrometer (AMS) was used in a previous study to give organic carbon and sulfate contents in ultrafine particles, but no black carbon and detailed molecular chemical components could be monitored (Lu et al., 2006). In addition, in-stack ship-based particle 
measurement was performed using a micro-orifice uniform deposit impactor (MOUDI) with offline analysis. The results showed that freshly emitted particles from ship exhaust comprised approximately $30 \%$ organic carbon and $70 \%$ sulfuric acid by mass (Murphy et al., 2009). However, chemical compositions and their characteristics in particles at different sizes emitted from ships are still unclear, especially for fine or ultrafine particles. Only one study investigated detailed PAH speciation and total $\mathrm{BaP}_{\mathrm{eq}}$ in size-segregated PM in the exhaust of a container ship with HFO and diesel oil (DO) as fuel and found that health risks increased with the decrease in particle size (Wu et al., 2018). Hence, it is urgent to gain detailed chemical compositions such as organic carbon (OC), EC and organic matter in size-segregated particles from different ships.

In this study, size-segregated particle samples from 12 different vessels were collected using an eight-stage cascade impactor. The mass, OC, EC, 16 EPA PAHs and $25 n$-alkanes in particles of each size bin were detected. Size-segregated distributions and characteristics of mass, OC, EC and the detected organic matter were given. The potential health impact, source apportionment and particle formation mechanism of ship exhaust were also explored in this study.

\section{Materials and methods}

\subsection{Tested vessels and fuels}

Size-segregated particle samples on quartz filters from 12 different vessels were collected in this study, including one heavy-fuel-oil ocean-going vessel, eight fishing boats, one engineering ship and two research ships. Their technical parameters are shown in Table S1. These vessels were classified into three types based on their engine type and fuel type, namely, the four-stroke low-power diesel fishing boat (4LDF), four-stroke high-power marine-diesel vessel (4-HMV) and two-stroke high-power heavy-fuel-oil vessel (2-HHV; see Table S1 for details). Notably, most of the vessels had high-speed marine engines in this study, except for YK and DFH, which had a low-speed engine and medium-speed engine, respectively. The parameters of all the fuels used for each tested vessel are shown in Table S2. Marine distillate oil was used as the fuel of the high-power-diesel vessels. Nonstandard marine distillate oil was used for the four-stroke low-power diesel fishing boats, which was introduced in our previous study (Zhang et al., 2016), while heavy fuel oil was used for the tested HFO vessel in this study. A total of 28 sets of size-segregated samples were obtained, as shown in Table S3. The main operating modes of each vessel were chosen according to actual operating conditions. More information about the sampling systems and fuels used for the tested vessels can be found in our previous studies (Zhang et al., 2016, 2018, 2019). Notably, the sampling system applied for the HFO vessel of YK was the same diluted system used for the fishing boats (see Fig. 1 for details).

\subsection{Sampling instrument}

An 8-Stage Andersen Cascade Impactor (TE-20-800, Tisch Environmental Inc, USA) was used for particle collection. The flow rate was $28.3 \mathrm{~L} \mathrm{~min}^{-1}$. The particles were separated into nine size bins by the impactor, and the particlesize range, sampling spot number or sampling area for each stage are shown in Table S4. The sampling duration for each sample varied from 10 to $30 \mathrm{~min}$, according to emission conditions and dilution ratios (see Table S3 for details).

\subsection{Chemical analysis}

The mass, organic carbon, element carbon, 16 priority PAHs indicated by US EPA (the detailed information is shown in Table S5) and $n$-alkanes from C10 to C34 in each particlesize bin were measured. The mass of the particles on each filter was obtained by the gravimetric method. OC and EC were measured with a $0.544 \mathrm{~cm}^{2}$ punch aliquot of each filter sample by thermal-optical reflectance (TOR) following the IMPROVE-A protocol with a DRI Model 2001 Thermal/Optical Carbon Analyzer (Atmoslytic Inc., Calabasas, CA). The measuring range of TOR was from 0.05 to $750 \mu \mathrm{g} \mathrm{C} \mathrm{cm}{ }^{-2}$, with an error of less than $10 \%$. The PAHs and $n$-alkanes were measured by an OPTIC- 4 thermal desorption (TD) sample injection port coupled with an Agilent GC7890B/MS5977A (Agilent Technologies, Santa Clara, CA) system (Han et al., 2018). The detailed information of the TD-GC/MS (thermal desorption-gas chromatographymass spectrometry) method for PAHs and $n$-alkanes was shown as follows.

Each of the collected Quartz filter samples was punched with an area of $5 \mathrm{~mm}$ in diameter, with a sampling spot as the center for PAHs and $n$-alkanes analysis. The filter was cut to small pieces and loaded into a TD glass tube; $1 \mu \mathrm{L}$ deuterium-marked compounds and hexamethylbenzene with concentrations of $10 \mathrm{ppm}$ were injected into the tube as internal standards. The TD glass tube was then placed into the TD inject port and was heated to $310^{\circ} \mathrm{C}$ at a rate of $12^{\circ} \mathrm{C} \mathrm{min}^{-1}$ and thermally desorbed at $310^{\circ} \mathrm{C}$ for $3 \mathrm{~min}$. The desorbed organic compounds were trapped on the head of a GC column (DB-5MS: $5 \%$ diphenyl - 95\% dimethylsiloxane copolymer stationary phase; $0.25 \mathrm{~mm}$ inner diameter - i.d.; $30 \mathrm{~m}$ length and $0.25 \mathrm{~mm}$ thickness). The initial $\mathrm{GC}$ oven temperature was $60^{\circ} \mathrm{C}$ and held for $4 \mathrm{~min}$; then it rose to $300^{\circ} \mathrm{C}$ at a rate of $6^{\circ} \mathrm{C} \mathrm{min}^{-1}$ and was held at $300^{\circ} \mathrm{C}$ for $8 \mathrm{~min}$ (Han et al., 2018). D8-Naphthalene, D10-acenaphthene, D10-phenanthrene, D12-chrysene, D12perylene, D-C16, D-C20, D-C24 and D-C30 were used for the analytical recovery check. The detection limit for the TD-GC/MS method ranged from $0.2 \mathrm{pg} \mathrm{mm}^{-2}$ (Ace) to $0.6 \mathrm{pg} \mathrm{mm}^{-2}$ (IcdP). 

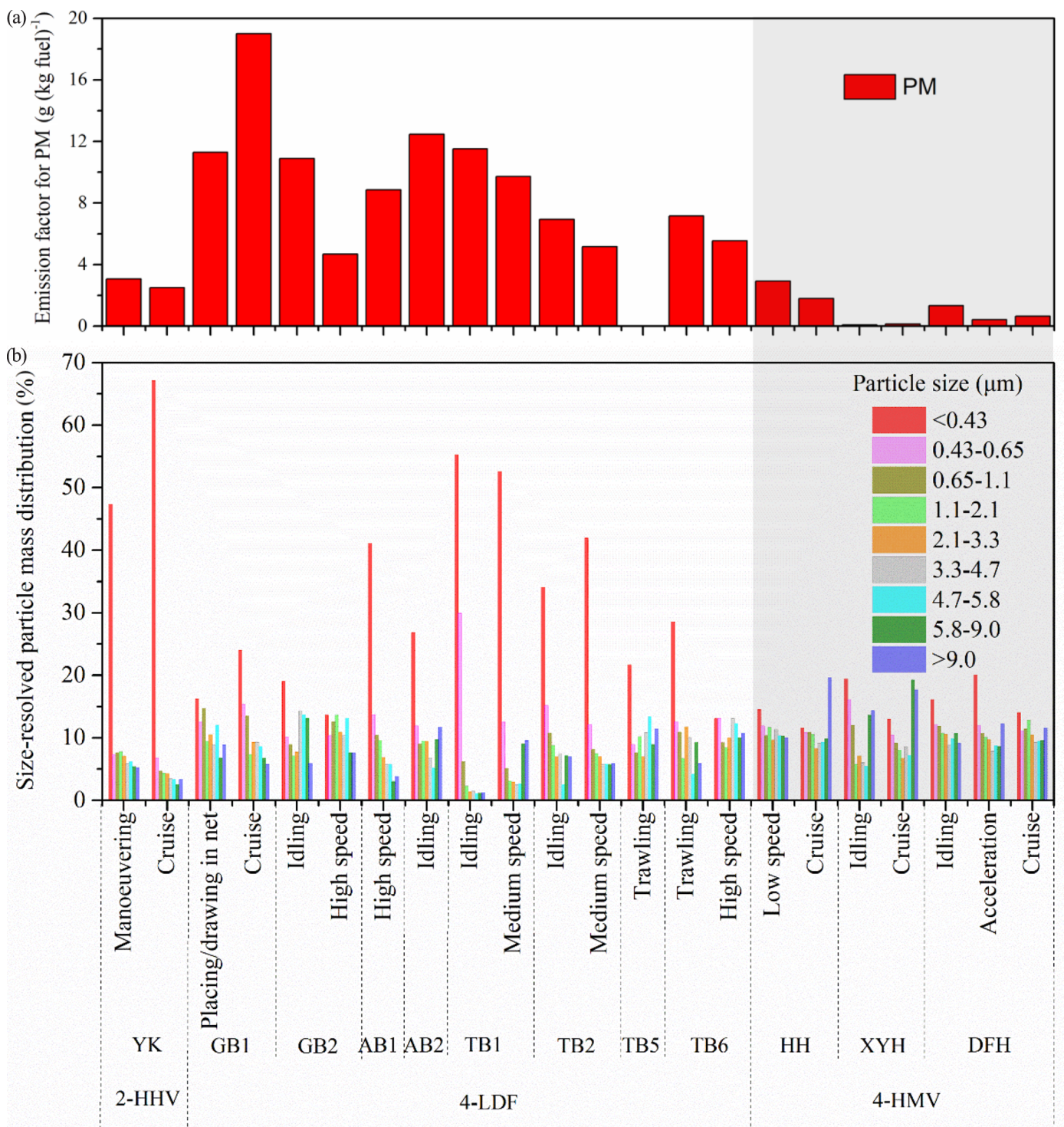

Figure 1. Emission factor for total PM and size-resolved particle mass distributions with different modes for the 12 tested ships (the vessels on the right in light gray used the undiluted system, and the rest of the vessels used the diluted system).

\subsection{Quality assurance and quality control}

Rigorous quality assurance and control were conducted during all experiments. Filter blanks were analyzed in the same way as the above procedures to determine the background concentration. Duplicate samples as well as standard samples were examined after analyzing a batch of 10 samples to ensure that the error was within $5 \%$. The average recoveries of the deuterium surrogates ranged from $84.3 \%$ to $101 \%$ in this study (shown in Table S6). The results of each sample were subtracted by the filter blank results. The final data reported in this study were not corrected by the recoveries.

\section{Results and discussions}

\subsection{Total mass distributions between different particle-size bins}

Emission factors for the total PM and particle mass size distribution of all of the 12 tested ships with different modes are shown in Fig. 1. The emission factor for PM was discussed in our previous studies (Zhang et al., 2016, 2018, 2019). In general, four-stroke low-power diesel fishing boats had much higher PM emission factors than other types of ships, while four-stroke high-power marine-diesel vessels showed lower PM emission factors, especially for the high-quality fuel ships. Notably, the four-stroke high-power marine-diesel vessels used an undiluted sampling system, which was inferred 
as one reason for the lower PM emission factors (Robinson, 2010). Besides this, low-load operating modes showed higher PM emission factors for almost all the tested ships. In this study, we focused on the particle mass size distribution of the tested ships. It was found that more than half of the particle mass was concentrated in fine particles with $D_{p}<1.1 \mu \mathrm{m}$ (33\%-91\%). However, there were still non-ignorable proportions $(5 \%-53 \%)$ in coarse particles with $D_{p}>3.3 \mu \mathrm{m}$. The findings were in line with the previous studies which reported that the mass distributions of ship emissions were dominated by accumulation-mode and/or coarse-mode particles (Moldanová et al., 2009, 2013; Murphy et al., 2009).

Different types of ships showed rather different particle mass size distributions. As shown in Fig. 1, the mass was concentrated on particles with $D_{p}<0.43 \mu \mathrm{m}$ for the HFOdriven ship YK, coincident with the results of a previous study that found that the particle mass peaked at around $50 \mathrm{~nm}$ for a HFO ship (Chu-Van et al., 2017) but inconsistent with a study on hot-exhaust particles from a HFO-driven cargo vessel, which revealed bimodal particle mass distribution with peaks at $\sim 7$ and $\sim 0.5 \mu \mathrm{m}$, attributed to the HFO combustion and the varying nature and composition of the ship-exhaust particulates (Moldanová et al., 2009). In this study we found that four-stroke high-power marine-diesel vessels had relatively smaller fractions of particle mass in the fine mode with $D_{p}<0.43 \mu \mathrm{m}$ but larger fractions in the coarse mode with $D_{p}>5.8 \mu \mathrm{m}$ than those of the HFO ship. This pattern was also consistent with the result of Fridell et al. (2008), who found a large peak at $\sim 10 \mu \mathrm{m}$ from the emissions of large diesel fuel engines. Furthermore, different fishing boats (GB1 to TB6 in Fig. 1.) showed different particle mass size distributions in this study. It can be seen that lowerengine-power fishing boats had high percentages of fine particles with $D_{p}<1.1 \mu \mathrm{m}$, while higher-engine-power fishing boats showed high proportions of coarse particles. The different particle mass size distributions for different types of ships were likely caused by the quality of fuel and its combustion efficiency in the engines and also the sampling method. For example, compared to diesel oil, HFO contains a high percentage of aromatics, which are known to contribute to nucleation-mode particle formation (Zetterdahl et al., 2017). Moreover, incomplete combustion could enhance the formation of nucleation-mode particles from the unburned fuel and lubrication oil (Zetterdahl et al., 2017). Hence, the relatively lower combustion efficiency of HFO ship led to higher proportions of fine particles than diesel-fueled ship. Moreover, the quality of fuel used for the same type of ships such as fishing boats varied largely in China, which might, at least to some extent, have also been responsible for the different size distributions. Compared to higher-engine-power fishing boats, relatively lower combustion efficiencies of the lowerengine-power fishing boats resulted in higher proportions of fine particles (Zhang et al., 2018). The use of an undiluted sampling system could be one reason for the lower proportions of fine particles of 4-HMV; it has been proved that un-

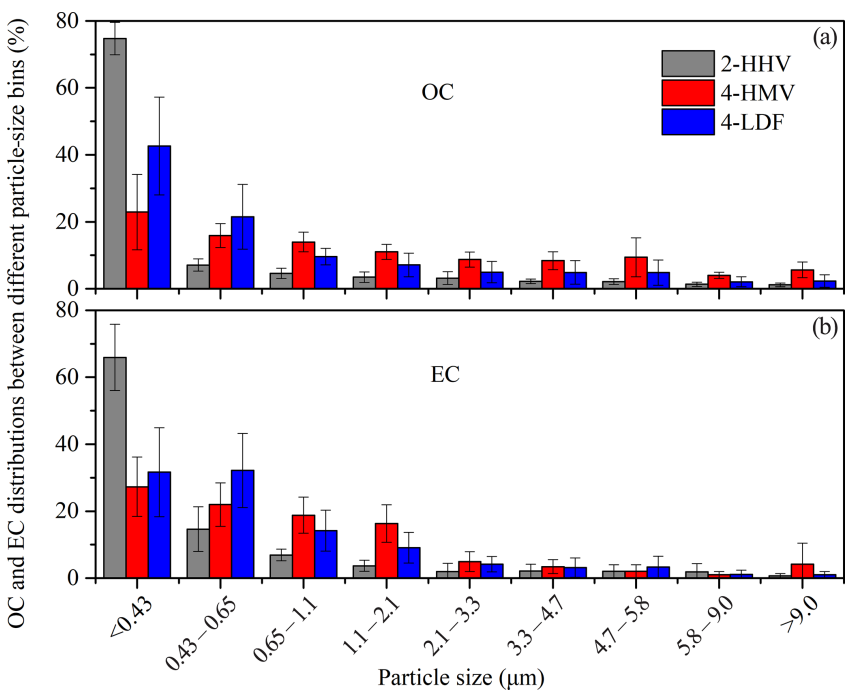

Figure 2. Total OC and EC distributions between different particlesize bins.

der the condition of the diluted sampling system, the soluble organic fractions could pass from the gas phase to the particle phase to form new particles (Heywood, 1988; Kittelson, 1998).

The particle mass size distribution in different operating modes of different ships was also compared in this study. The results showed that when the ships were operated with higher engine loads, there were more particles in coarse modes for most of the ships, which was similar to a previous study on mass distribution from measurements aboard three ships (Fridell et al., 2008). Besides this, a previous study on a marine engine reported that the particle mass distribution centered at $0.1-0.2 \mu \mathrm{m}$ with much fewer coarse particles under the at-berth condition with the auxiliary engine compared to maneuvering and ocean-going conditions (Chu-Van et al., 2017). Coincidently, emissions from two auxiliary engines in the HFO-driven ship YK and engineering ship HH were measured in this study (Fig. S1). Both showed high proportions of fine particles with $D_{p}<0.43 \mu \mathrm{m}$ and small percentages of coarse particles, similar to the findings of Chu-Van et al. (2017). Overall, the fuel type, fuel quality, engine type and operating mode might have a comprehensive influence on particle mass distributions from ships.

\subsection{Characteristics of $\mathrm{OC}$ and $\mathrm{EC}$ in size-segregated particles}

\subsubsection{The OC and EC mass distributions between different particle-size bins}

Figure 2 and Table $\mathrm{S} 7$ present the total OC and EC mass distributions between different particle-size bins for the three ship types. Notably, OC and EC levels given in this study were the average values of all samples that were classified 
into these three types. The OC and EC distributions between different particle-size bins showed similar but distinguished characteristics compared to the PM mass distribution. All the tested ships presented similar trends; namely, the proportions of OC and EC decreased with the increase in particle size. About $53 \%-86 \%$ of OC and $68 \%-86 \%$ of EC were in the particles with $D_{p}<1.1 \mu \mathrm{m}$. Only very small percentages of $\mathrm{OC}$ and EC existed in the coarse particles. Among the three types of ships, 2-HHV showed significantly higher OC and EC proportions in particles with $D_{p}<0.43 \mu \mathrm{m}(75 \%$ and $66 \%$, respectively) than the other two types of ships operated with diesel fuel, while the OC and EC proportions were lower in the other particle-size bins of 2-HHV than those of the other two types of ships. For example, 4-HMV only accounted for $23 \%$ OC and $27 \%$ EC in particles with $D_{p}<0.43 \mu \mathrm{m}$ compared to 2-HHV, which had $75 \%$ OC and $66 \%$ EC in particles with $D_{p}<0.43 \mu \mathrm{m}$. This is in accordance with the characteristics of total PM mass distributions; that is, diesel fuel vessels had relatively smaller proportions of fine particles with $D_{p}<0.43 \mu \mathrm{m}$ and larger proportions of coarse-mode particles than HFO ships. Notably, the proportion of EC in particle-size bins of $0.43-0.65 \mu \mathrm{m}$ had almost the same level as that in particle-size bins of less than $0.43 \mu \mathrm{m}$ for 4 -LDF. The higher proportions of OC and EC in fine particles from the HFO-driven vessel compared to the diesel fuel ships might be attributed to both the combustion efficiency and the use of HFO. Due to the large fuel-to-air ratio in the HFO engine (Kittelson et al., 1998), higher fractions of unburned fuel with a heavier molecular weight as well as lubrication oil could more easily leak into the exhaust and raise the carbonaceous fractions (Hardy and Reitz, 2006). Besides this, the incomplete combustion and the high content of aromatics in HFO could both enhance the formation of new nucleation-mode particles (Zetterdahl et al., 2017), which would eventually promote a high fraction of fine mode carbonaceous particles.

\subsubsection{OC and EC proportions in each particle-size bin}

In order to figure out the carbonaceous components in sizesegregated particles, percentages of $\mathrm{OC}$ and $\mathrm{EC}$ in each particle-size bin are given in Fig. 3. In general, both OC and EC proportions showed overall decreasing trends with the increase in particle sizes for all three types of ships. OC $+\mathrm{EC}$ accounted for large proportions of the total particle mass in fine particles, between $40 \%$ and $65 \%$ for particles smaller than $0.65 \mu \mathrm{m}$. However, OC + EC only explained small proportions in coarse particles, less than $15 \%$ for particles larger than $5.8 \mu \mathrm{m}$ diameter, suggesting that most of the coarse particle mass was dominated by other non-carbonaceous compounds, such as ash and hydrated sulfates. The coarse particles could be seriously influenced by naturally based substances such as ash that were introduced into the cylinder by the air to maintain a certainly reliable equivalent ratio in the cylinder. This was confirmed in a previous study about

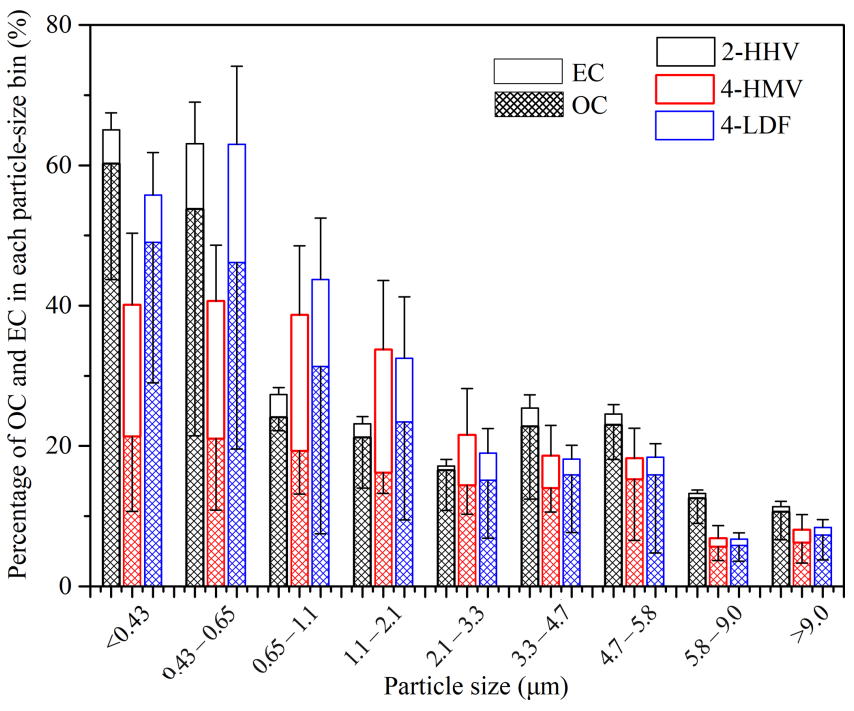

Figure 3. Percentage of OC and EC mass in each particle-size bin (the upper error bar represents the standard deviation of EC, and the lower error bar represents the standard deviation of OC).

the ship-exhaust particle composition based on a transmission electron microscopy (TEM) study. Mineral or ash particles containing lime, calcite, vanadium oxide and nickel sulfide were also found to be dominant in coarse particles (Moldanová et al., 2009).

In addition, the differences of $\mathrm{OC}+\mathrm{EC}$ proportion patterns among the three types of ships were large. OC $+\mathrm{EC}$ accounted for $>60 \%$ in particles with $D_{p}<0.65 \mu \mathrm{m}$ for 2HHV, then decreased sharply to less than $30 \%$ in particles with $D_{p}>0.65 \mu \mathrm{m}$, and only explained $\sim 10 \%$ in particles with $D_{p}>9.0 \mu \mathrm{m}$. OC + EC for 4-LDF showed a similar trend to that for 2-HHV but had higher proportions in particles with $D_{p}$ of $0.65-3.3 \mu \mathrm{m}$. In contrast, $\mathrm{OC}+\mathrm{EC}$ only accounted for $\sim 40 \%$ in particles with $D_{p}<1.1 \mu \mathrm{m}$ for $4-$ HMV and decreased to less than $10 \%$ in particles with $D_{p}>9.0 \mu \mathrm{m}$. Because the OC and EC compositions in sizesegregated particles from ships were not studied in the past, this study compared components of $\mathrm{PM}_{1}$ or hydrated sulfate and organic carbon in size-resolved particles with earlier studies. Diesch et al. (2013) found that organic matter $(\mathrm{OM})$ was the most abundant component in $\mathrm{PM}_{1}$, while EC contributed only $6 \%$ on average to $\mathrm{PM}_{1}$. This result was similar to the composition of 2-HHV emissions in this study but significantly different from that of the 4-HMV and 4-LDF, likely due to the different types of engine and fuel. Moreover, Healy et al. (2009) found that hydrated sulfate and organic carbon were the dominant components of size-resolved PM from ship plumes, while Murphy et al. (2009) reported that the fraction of unknown mass was much higher at small particle sizes, which were different from our results. The large discrepancies might be caused by the different sampling, analytical methods and the fuel quality. In addition, the uniden- 


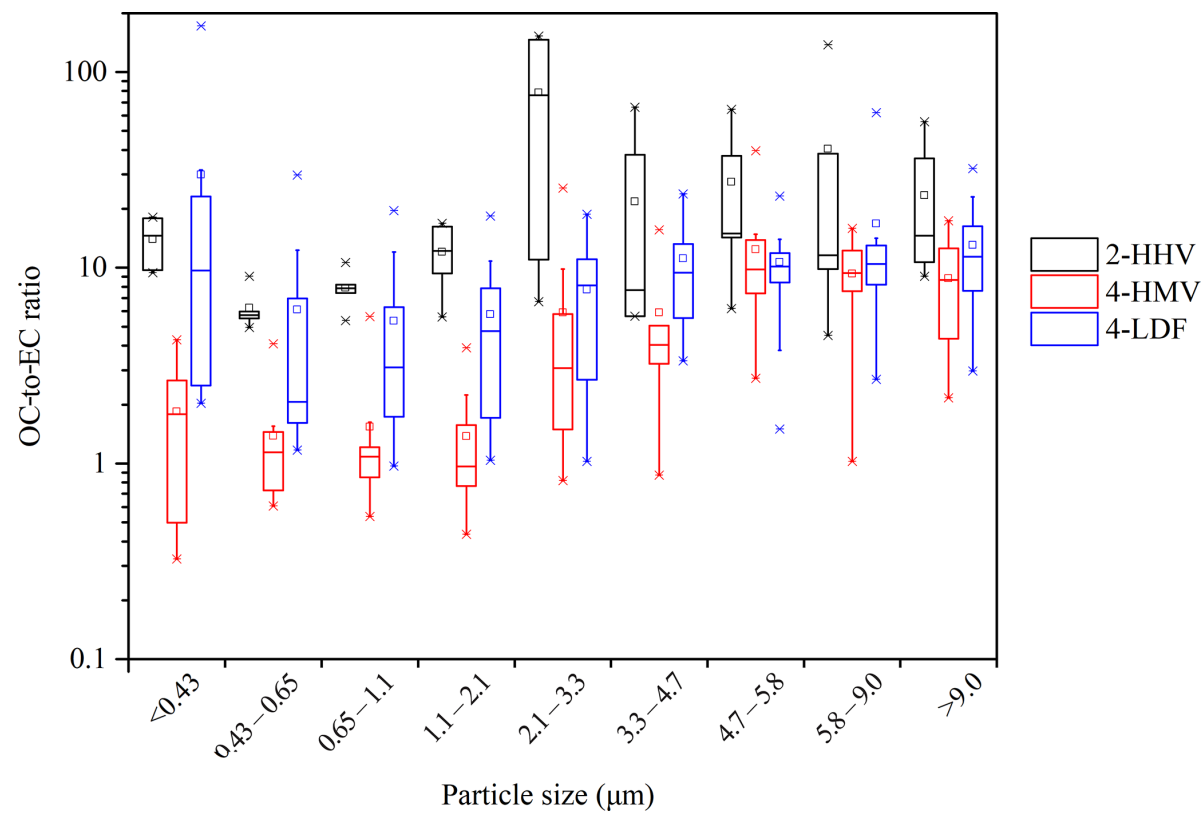

Figure 4. OC / EC ratio in different particle-size bins.

tified components in each particle-size bin should be clarified in the future, especially in coarse particles.

The average proportions of OC were higher than EC in each individual particle-size bin for all the tested ships. For better comparison, OC / EC ratios in all particle-size bins are given for the three types of ships in Fig. 4. The OC / EC ratio of 2-HHV in each particle-size bin was the highest, followed by 4-LDF and 4-HMV. The OC / EC ratios in fine particles from $2-\mathrm{HHV}$ were more than 10 , while they were less than 3 for 4-HMV. In addition, with the increase in particle size, the $\mathrm{OC} / \mathrm{EC}$ ratios decreased first and then increased, with the lowest values in particle sizes of $0.43-1.1 \mu \mathrm{m}$. However, all the ships had similar median OC / EC ratios of $\sim 10$ in coarse particles with $D_{p}>4.7 \mu \mathrm{m}$.

It is well known that particles emitted from diesel engines are formed through a complex process, starting with soot precursors generated from thermal decomposition of the large hydrocarbon molecules, through processes such as dehydrogenation, PAH formation, growth in molecular weight, particle inception, growth by surface reaction and coagulation, agglomeration and oxidation, etc. (Lighty et al., 2000). In these processes, several factors can influence the size of the emitted particles: (1) surface growth involves the attachment of gas-phase species to the existing particles and results in an increase in PM diameter and mass, (2) aggregation leads to chains and clusters of primary soot particles and an increase in particle size (to $10-100 \mathrm{~nm}$ in diameter; Heywood, 1988), and (3) oxidation occurs during the formation and growth processes of the particles, resulting in the formation of gaseous species and reduction of soot particles and their precursors. In addition, the exhaust gases continue to cool down and are diluted with air in the exhaust gas channel. The decreased temperature has an impact on the condensation and adsorption of hydrocarbons and other volatile compounds but not on the soot particles (Heywood, 1988). The volatile compounds in the exhaust gas channel may form new particles via transformation, nucleation, adsorption and condensation, depending on the conditions in the exhaust gas channel (Kittelson, 1998).

Soot particles are mainly formed through pyrolysis of diesel fuel and lubrication oil, and the organic fraction is formed through the incomplete combustion of fuel and lubrication oil (Zetterdahl, 2016). Incomplete combustion of fuel and lubrication oil can significantly enhance the formation of fine particles, which might be the reason for the higher OC / EC ratio in particles with $D_{p}<0.43 \mu \mathrm{m}$ in this study. This study also found that most EC was in the particles with $D_{p}<1.1 \mu \mathrm{m}$, coincident with the fact that soot is primarily in the accumulation mode with particles of $0.1<D_{p}<1 \mu \mathrm{m}$ (Kasper et al., 2007). Although OC was also concentrated in fine particles with $D_{p}<1.1 \mu \mathrm{m}$ (Sect. 3.1), its percentage was higher in particles with $D_{p}<0.43 \mu \mathrm{m}$ and lower in particles with $0.43<D_{p}<1.1 \mu \mathrm{m}$, compared to the EC distribution. Therefore, OC/EC ratios were the lowest in particles with $0.43<D_{p}<1.1 \mu \mathrm{m}$ for all the tested ships. For the coarse particles in this study, though non-carbonaceous compounds were the dominant parts, OM increased after the cooling of the exhaust gas, while content of EC and ash remained unchanged through adsorption of hydrocarbons and other volatile compounds (Zetterdahl, 2016; Heywood, 1988), which enhanced the mass of coarse particles. Consequently, OC/EC ratios also showed high values in 

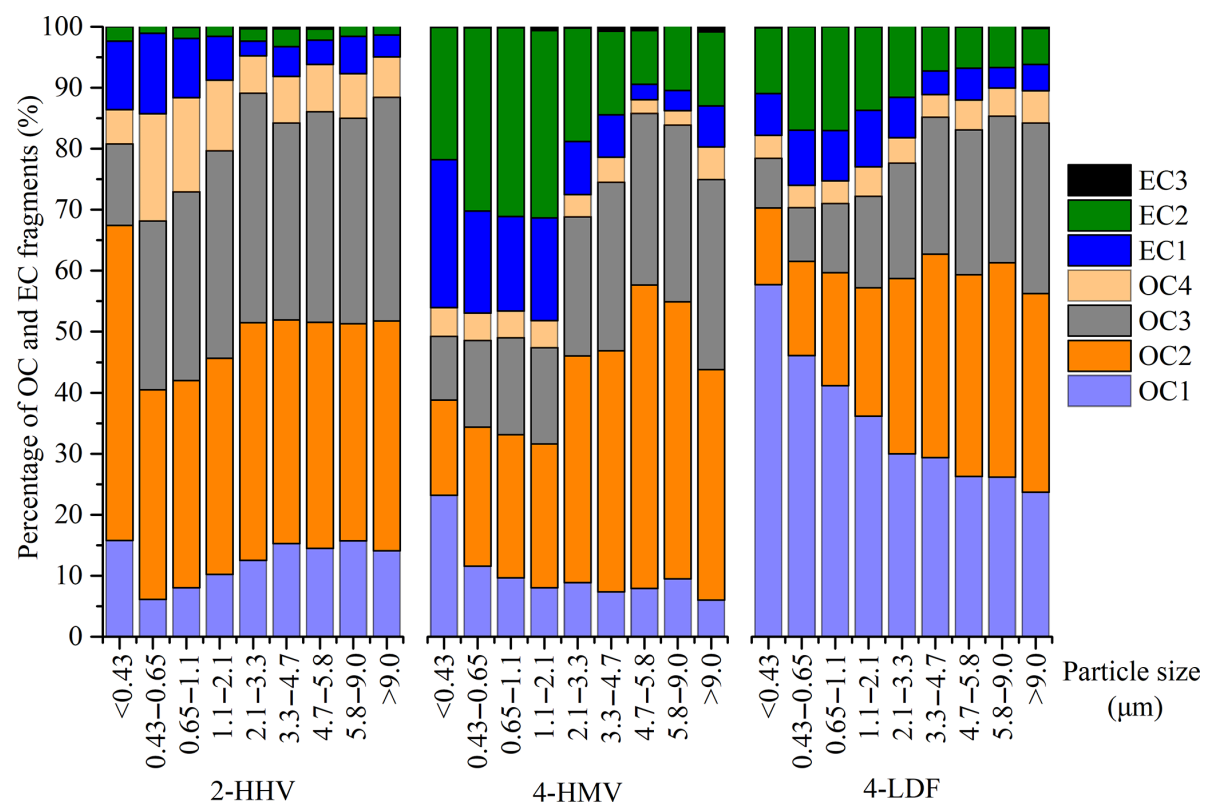

Figure 5. Percentage of OC and EC fragments in different particle-size bins.

coarse particles with $D_{p}>3.3 \mu \mathrm{m}$. 2-HHV showed a higher OC / EC ratio than the diesel fuel ships of both 4-HMV and 4LDF, which might be caused by the relatively lower combustion efficiency and higher EC emissions of 4-LDF (Zhang, 2018). Similarly, because 4-HMV ships had higher combustion efficiencies due to the higher fuel quality and better engine maintenance in this study and also to the influence of the use of an undiluted sampling system that is adverse to the transmission of gas-phase organic matter to particle phase (Heywood, 1988; Kittelson, 1998), OC / EC ratios of 4-HMV showed the lowest levels.

\subsubsection{OC and EC fragments in size-segregated particles}

According to the IMPROVE-A protocol used in the thermaloptical carbon analysis, fragments of $\mathrm{OC}(\mathrm{OC} 1, \mathrm{OC} 2, \mathrm{OC} 3$ and OC4 fragments obtained in $120,250,450$ and $550^{\circ} \mathrm{C}$ in a pure $\mathrm{He}$ atmosphere, respectively) and EC (EC1, EC2 and EC3 fragments obtained in 550,700 and $840{ }^{\circ} \mathrm{C}$ in the $98 \%$ $\mathrm{He}$ and $2 \% \mathrm{O}_{2}$ atmosphere, respectively) were obtained and used to understand different formation processes (Sippula et al., 2014). In this study, percentages of OC and EC fragments in different particle-size bins are shown in Fig. 5. Typically, OC1 + OC2 was classified as volatile organic compounds, while OC $3+\mathrm{OC} 4$ was categorized as refractory organic compounds. EC was divided into char and soot. EC1 was classified as char EC, and EC2 + EC3 was classified as soot EC (Han et al., 2018). OC1, OC2 and OC 3 were the dominant OC fragments for all the tested ships, while EC2 was the prevailing EC fragment for diesel fuel ships and EC1 was the main EC fragment for HFO ship. In comparison, OC1 + OC2 in 4-LDF ships accounted for higher per- centages than other types of ships, especially OC1, while $\mathrm{OC} 3+\mathrm{OC} 4$ in 2-HHV had more fractions than in 4-LDF and 4-HMV, revealing that more pyrolytic organic matter was emitted from 2-HHV ships.

The results are consistent with a previous study which found that $37 \%-57 \%$ of the OC was heavier OC fragments (OC3, OC4 and pyrolytic carbon) in PM emitted from heavyfuel-oil ships, while the PM from diesel fuel ships was dominated by the most-volatile OC1 and OC2 fragments (Sippula et al., 2014). Since OC was mainly formed through incomplete combustion of the fuel and lubrication oil, the different OC fragments in PM between HFO and diesel fuel ships (4LDF and 4-HMV) reflected the variations in the fuel composition. This result was coincident with the fact that heavy fuel oil has longer carbon chains than diesel fuel. For EC, the number of soot particles emitted from cylinder depends on the difference between the formation rate and the oxidation rate during the expansion stroke (Zetterdahl, 2016). From Fig. 5 we inferred that the two-stroke low-speed HFO engine (2-HHV) had a higher oxidation rate than the fourstroke medium-high-speed diesel engines (4-HMV and 4$\mathrm{LDF}$ ), leading to lower soot EC percentages.

The OC and EC fragments had different percentages in different size particles. On one hand, OC1 in diesel fuel ships presented an obvious decreasing trend with the increase in particle size. However, though the highest proportion of OC1 was observed in particles with $D_{p}<0.43 \mu \mathrm{m}$ for 2-HHV, there was an opposite variation trend of the other particle-size bins to that of diesel fuel ships. Furthermore, for diesel fuel ships, both OC 2 and OC 3 had lower proportions in small particles and higher proportions in coarse particles. For 2-HHV, OC2 accounted for the largest proportion in particles with 
$D_{p}<0.43 \mu \mathrm{m}$, whereas its proportion in other particle-size bins was similar. In contrast, OC3 occupied the smallest proportion of 2-HHV in particles with $D_{p}<0.43 \mu \mathrm{m}$ and was constant in other particle-size bins. In addition, OC4 showed no significant variations among the particle-size bins for all the tested ships. On the other hand, EC1 showed decreasing trends with the increase in particle size for all the tested ships, while EC2 had the highest proportions in particles with $0.65<D_{p}<1.1 \mu \mathrm{m}$ for diesel fuel ships, with overall higher proportions in small particles and lower proportions in coarse particles. However, EC2 of 2-HHV showed no significant variations. In addition, EC3 had very small proportions for all the tested ships and showed no significant variations with particle sizes.

It is known that particles in the nucleation mode consist of both solid particles and condensable organic and sulfur compounds that are usually formed during dilution and cooling of the exhaust gas (Kittelson, 1998). Hydrocarbons and carbon fragments are the main source of tiny particles from engines running under normal conditions with low-sulfur fuels (Kittelson, 1998). Besides this, it has been proved that new particle formation via nucleation is more favorable than adsorption on exiting particles if there is small surface area on which to adsorb when hydrocarbons transfer from the gas phase to the particle phase (Kittelson, 1998). Therefore, high volatile organic matter in nucleation-mode particles might be the reason for higher proportions of $\mathrm{OC} 1$ in small particles. It is also known that the majority of accumulation-mode particles are solid agglomerates with adsorbed compounds (Kittelson, 1998). Due to the smaller relative surface areas of accumulation and coarse-mode particles, less volatile organic matter can be adsorbed with the increase in particle size, leading to the decreased proportions of OC1. In addition, OC3 and OC4 stem from low-volatile organic matter with large molecular weights, which might be formed directly inside the cylinder under high temperature and pressure. The existence and formation of large-sized particles containing OC 3 and OC4 have been proved in a previous study (Han et al., 2018). In this study, EC was primarily found in the accumulation mode. This is to some extent consistent with the findings of Kittelson (1998) that accumulation-mode particles are mainly carbonaceous soot agglomerates formed directly by combustion, and those of Moldanová et al. (2009) that char and char-mineral particles were concentrated in a size range of $0.2-5 \mu \mathrm{m}$. Moreover, the decreased temperature in the exhaust gas channel has an impact on the condensation and adsorption of hydrocarbons and other volatile compounds during the coarse particle formation but not on the soot particles (Heywood, 1988). As a result, EC fragments showed obvious deceasing trends with the increase in particle size in the coarse mode. The formation of OC and EC fragments could be influenced by many factors, such as the engine condition (temperature and pressure), fuel type (fuel composition and structure), operating conditions, etc. (Tree and Svensson, 2007). However, detailed formation mecha- nisms of OC and EC fragments in size-segregated particles still need to be further studied.

\subsection{Characteristics of PAHs and $\boldsymbol{n}$-alkanes in size-segregated particles}

\subsubsection{Distributions of total PAHs and total $\boldsymbol{n}$-alkanes between different particle-size bins}

The distributions of total PAHs and total $n$-alkanes in different size particles emitted from these three types of ships in China are shown in Fig. 6 and Table S8. Similarly to OC and EC, the levels of PAHs and $n$-alkanes provided in this study were the average values of all samples that were classified into these three types. Clearly, large proportions of identified organic compounds were concentrated in fine particles. About $66.3 \%$ to $88.0 \%$ of PAHs were in particles with $D_{p}<1.1 \mu \mathrm{m}$. The results are consistent with the finding of a previous study that revealed that $>69 \%$ particle PAH was associated with $\mathrm{PM}_{2.5}$ emitted from residential coal combustion (Shen et al., 2010). Similar observations were also reported from indoor crop burning (Shen et al., 2011) and motorcycles (Yang et al., 2005). In addition, a previous study about PM from a typical container ship demonstrated that the smaller the particles are, the greater their toxicity is $(\mathrm{Wu}$ et al., 2018). In comparison, $n$-alkanes in fine particles with $D_{p}<1.1 \mu \mathrm{m}$ accounted for higher proportions than PAHs, with a range of $79.0 \%-94.6 \%$. Both PAHs and $n$-alkanes in particles with $D_{p}<1.1 \mu \mathrm{m}$ from 2-HHV had the highest proportions among the three types of ships, and they were the lowest from 4-HMV. Thus, large proportions of PAHs $(33.7 \%)$ and $n$-alkanes $(21.0 \%)$ were still in particles with $D_{p}>1 \mu \mathrm{m}$ for 4-HMV, which were seldom reported in previous studies of ship engine exhausts.

It is well documented that incomplete combustion of fuel and lubrication oil was one of the major sources of organic compounds in PM and enhanced the new particle formation (Agrawal et al., 2010; Zetterdahl et al., 2017). Higher PAH contents in heavy fuel oil and lower combustion efficiencies in two-stroke low-speed engines could lead to enhanced nucleation-mode particle formation, which could contain more PAHs and $n$-alkanes. In contrast, lower PAH contents in diesel fuel of 4-HMV ships, together with better maintenance of the engines, might lead to better combustion conditions and less nucleation-mode particle formation that had lower organic-matter proportions. In addition, new particles could be formed in the exhaust gas channel through the transformation of nucleation, adsorption and/or condensation. Therefore, the varied conditions in the exhaust gas channels caused the differences in organic-matter proportions in coarse particles. The relatively longer exhaust gas channel in the channel of 2-HHV enhanced the formation of new secondary nucleation-mode and/or accumulation-mode particles from gas-phase organic compounds, leading to higher pro- 


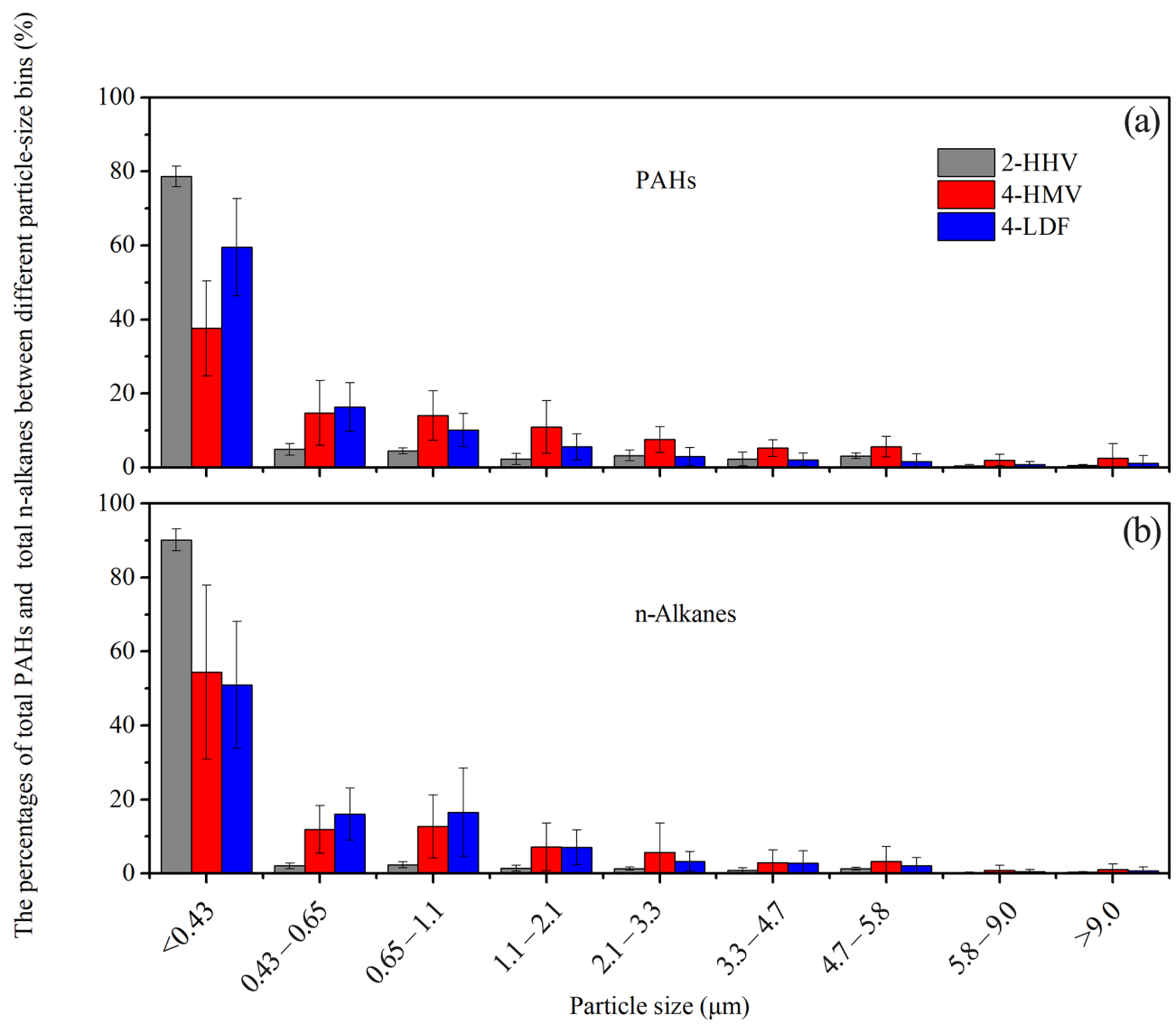

Figure 6. The distribution of total PAHs and total $n$-alkanes between different particle-size bins (\%).

portions of organic matter in fine particles, which has been proved in a previous study (Kittelson, 1998).

\subsubsection{Emission ratios of PAHs and $\boldsymbol{n}$-alkanes in each particle-size bin}

In order to explore the variations in total PAHs and total $n$-alkanes in different size particle bins, the emission ratio $\left(\mu \mathrm{g}\left(\mathrm{g}^{-1} \mathrm{PM}\right)\right.$ and $\left.\mathrm{mg}\left(\mathrm{g}^{-1} \mathrm{PM}\right)\right)$ was defined and discussed in this study. It is calculated by dividing the total PAHs or $n$ alkanes mass $\left(\mu \mathrm{g} \mathrm{mg}^{-1}\right)$ through the particle mass $(\mathrm{g})$ in each particle-size bin. The emission ratios of total PAHs and total $n$-alkanes in size-segregated particles are shown in Fig. 7. Obviously, the emission ratios of both PAHs and $n$-alkanes decreased with the increase in particle size, and they were more than 2 orders of magnitude higher in fine particles than in coarse particles. Namely, much more organic matter was contained in fine particles than in coarse particles. This is consistent with previous findings that nucleation-mode particles usually contain a large proportion of organic compounds (Kittelson, 1998; Moldanová et al., 2009).

Among the three types of ships, 4-LDF had the highest PAH emission ratios in fine particles with $D_{p}<1.1 \mu \mathrm{m}$, and the 2-HHV had the lowest values. However, no significant difference of PAH emission ratios was observed in particles with $D_{p}>1.1 \mu \mathrm{m}$ for all the tested ships $(p>0.05)$ as for $n$ alkanes. In particular, the four-stroke low-power diesel fuel fishing boats in China had not only high levels of PM emission factor but also a high proportion and emission ratio of organic matter in fine particles, implying their severe influence on human health and the environment.

\subsubsection{Profiles of speciated PAHs and $\boldsymbol{n}$-alkanes in size-segregated particles}

The speciated profiles of PAHs and $n$-alkanes in sizesegregated particles emitted from the three types of ships are shown in Fig. 8. Phe, Flua, Pyr, BaA, Flu and Chr (full names and their abbreviations are shown in Table S5) were the most dominant PAHs, while their relative percentages in different types of ships and in different particle-size bins varied. For 2-HHV, the levels of Flua, Phe, BaA and Pyr were higher than other PAH species, while the profiles of PAHs in different particle sizes were similar. For 4-HMV, Phe, Flu, BaA and Pyr were the main PAHs, with Phe having the highest proportions in all the particle-size bins. Furthermore, the percentages of Phe and $\mathrm{BaA}$ were lower in coarse particles. This is in accordance with the fact that synthetic 

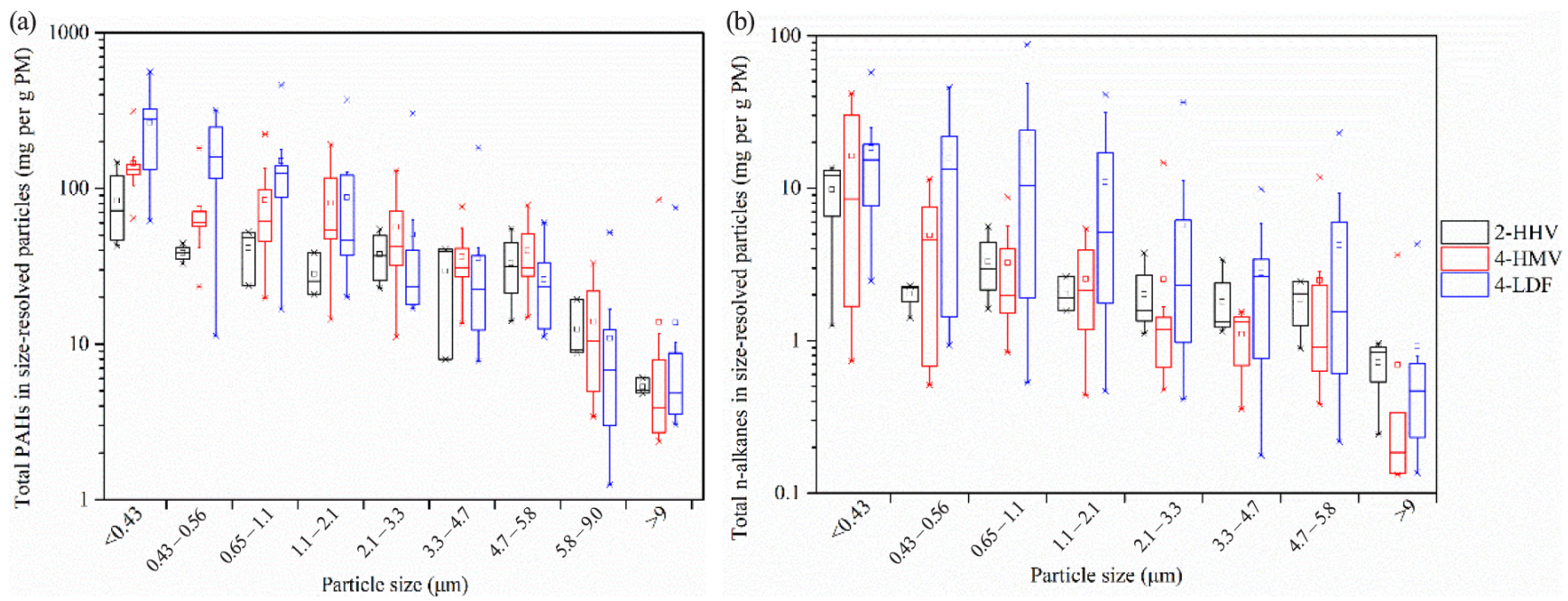

Figure 7. Emission ratios of total PAHs (in $\mu \mathrm{g}\left(\mathrm{g}^{-1} \mathrm{PM}\right)$ ) and $n$-alkanes (in $\mathrm{mg}\left(\mathrm{g}^{-1} \mathrm{PM}\right)$ ) in size-resolved particles

PAHs have higher concentrations in freshly formed particles (Pergal et al., 2013). However, the percentages of Pyr and Chr increased with the increase in particle size. For 4-LDF, Pyr, $\mathrm{BaA}$, Phe, Flua and $\mathrm{Chr}$ were the dominant components. The percentage of BaA decreased with the increase in particle size, whereas Pyr and Chr presented opposite trends. The various profiles of PAHs in different particle-size bins indicated their different formation processes, which were likely related to the fuel quality, engine type and the condition in the exhaust gas channel (Lombaert et al., 2006). It should be noted that when diagnostic characteristics of PAHs in PM emitted from ships are used in source apportionment, particle size needs to be taken into consideration.

The ratio of high-molecular-weight (HMW) PAH (four to six rings) to low-molecular-weight (LMW) PAH (two and three rings) is shown in Fig. S2. The 4-LDF had the highest HMW / LMW ratios (2.96-8.25), while the 4-HMV had the lowest ratios $(0.62-1.98)$. The results indicated that 4-LDF and 2-HHV had unfavorable combustion conditions compared to 4-HMV, which is consistent with our previous conclusion. The HMW / LMW ratios were generally higher in fine particles and decreased with the increase in particle size, except for 2-HHV, which still showed high ratios when particle size was larger than $5.8 \mu \mathrm{m}$. Since HMW PAHs have high toxic equivalence (TEQ), the higher HMW / LMW PAHs ratios in fine particles implied that small particles emitted from the three types of ships might be more toxic than coarse particles. Furthermore, from our previous study the 4-LDF showed not only higher HMW / LMW ratios than other ships but also much higher amounts of total PAH emission (Zhang et al., 2019), implying the necessity of more stringent control on the emissions of particles from fishing boats in China.

From Fig. 8, it can be seen that $n$-alkanes showed different percentage distributions between different particle-size bins from different types of ships. There were larger maxi- mum carbon numbers $\left(C_{\max }\right)$ in smaller size particles, such as $C_{20} / C_{21}$ for 2-HHV, $C_{21} / C_{22}$ for 4-HMV and $C_{21} / C_{22}$ for 4-LDF. However, with the increase in particle size, the $C_{\max }$ of $n$-alkanes switched to $C_{18} / C_{19}, C_{20} / C_{21}$ and $C_{18} / C_{19}$ for 2-HHV, 4-HMV and 4-LDF, respectively. Similar to PAHs, when diagnostic characteristics of $n$-alkanes in PM emitted from ships is used in source apportionment, particle size needs to be taken into consideration.

\section{Conclusions and implications}

Particulate matter emitted from ships has gained more and more attention in recent years due to its adverse impacts on human health and ambient air quality. However, our knowledge on the abundance and chemical speciation in different particle sizes is limited. In this study, size-segregated distributions and characteristics of mass, OC, EC, 16 PAHs and 25 $n$-alkanes from 12 different vessels in China were presented.

This study found that over $50 \%$ of the total particle mass was explained by the particles with $D_{p}<1.1 \mu \mathrm{m}$ for most of the tested ships. Specifically, the mass was concentrated in particles with $D_{p}<0.43 \mu \mathrm{m}$ for 2-HHV, and in particles with $D_{p}<1.1 \mu \mathrm{m}$ for lower power diesel fuel fishing boats, while the mass accounted for higher percentages by coarse particles for higher-power diesel fuel fishing boats and 4-HMV.

Similar to the total particle mass distribution, about $53 \%$ $86 \%$ of total OC and $68 \%-86 \%$ of total EC were in the particles with $D_{p}<1.1 \mu \mathrm{m}$, presenting a downward trend with the increase in particle size. OC $+\mathrm{EC}$ accounted for major proportions of the total particle mass in fine particles. However, OC + EC only explained small proportions in coarse particles, suggesting that most of the coarse particle mass was dominated by other non-carbonaceous compounds. In addition, the $\mathrm{OC} / \mathrm{EC}$ ratio of 2-HHV in each particle-size bin was the highest, followed by 4-LDF and 4-HMV. With 

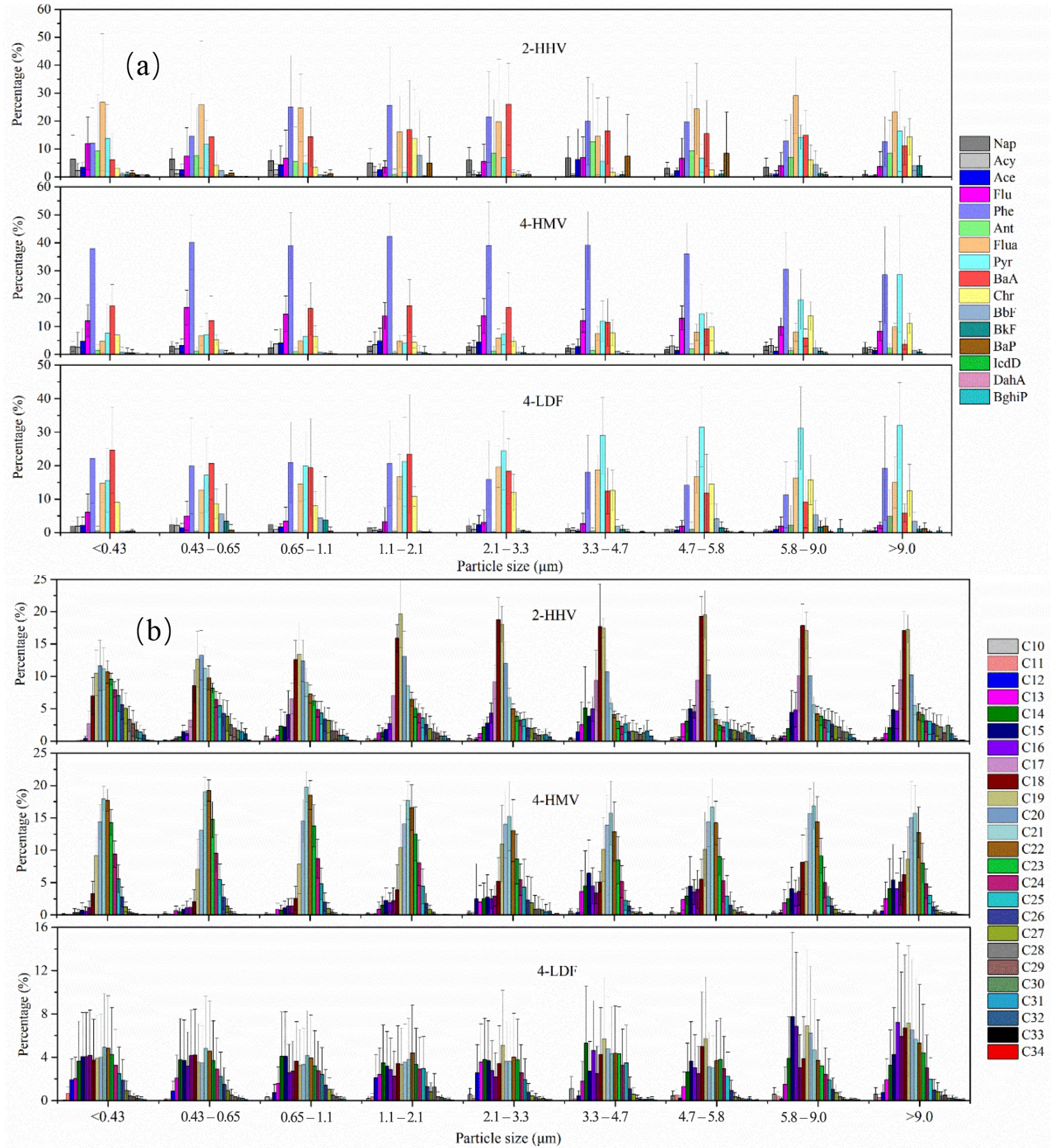

Figure 8. Speciated profiles of PAHs (a) and $n$-alkanes (b) in size-resolved particles. 
the increase in particle size, the OC / EC ratios decreased first and then increased, with the lowest values in particle sizes of 0.43-1.1 $\mu \mathrm{m}$. Moreover, fragments of OC and EC were obtained and used to understand different formation processes. $\mathrm{OC} 1, \mathrm{OC} 2$ and $\mathrm{OC} 3$ were the dominant $\mathrm{OC}$ fragments for all the tested ships, while EC2 was the prevailing EC fragment for diesel fuel ships and EC1 was the main EC fragment for HFO ship. Different OC and EC fractions showed different distributions between different particle-size bins because of the different formation mechanisms.

Sixteen PAHs and $25 n$-alkanes in different particle bins were identified in this study. Results showed that large proportions of the organic compounds were concentrated in fine particles, with about $66.3 \%-88.0 \%$ of PAHs and $79.0 \%-$ $94.6 \%$ of $n$-alkanes being in particles with $D_{p}<1.1 \mu \mathrm{m}$. 4-LDF had the highest PAHs and $n$-alkanes emission ratios in fine particles with $D_{p}<1.1 \mu \mathrm{m}$, and the 2-HHV had the lowest values, but no significant differences were observed in particles with $D_{p}>1.1 \mu \mathrm{m}$. Results of the speciated profiles of PAHs showed that Phe, Flua, Pyr, BaA, Flu and $\mathrm{Chr}$ were the most dominant PAHs, while their relative percentages in different types of ships and between different particle-size bins varied. In addition, the ratios of HMW PAHs to LMW PAHs were generally higher in fine particles and decreased with the increase in particle size; $n$-alkanes also showed different percentage distributions between different particle-size bins from different types of ships. Moreover, there were larger $C_{\max }$ values in smaller-sized particles, but these switched to smaller $C_{\max }$ values with the increase in particle size for all the tested ships.

This study confirmed that the particle mass distributions in different size bins from ships were significantly different from the particle number distributions, and different types of ships had their own distinct mass distributions. The different profiles of chemical components in size-segregated particles implied that size-segregated chemical profiles should be considered when source apportionment is conducted. Furthermore, this study found more toxic organics such as PAHs in small particles emitted from fishing boats, suggesting the necessity of more stringent control on this type of boat in China. In addition, detailed formation mechanisms of chemical composition in size-segregated particles need in-depth investigation. Finally, the large proportion of unidentified components in coarse particles still needs to be figured out. Due to the limitation of instrumental analysis, only very small proportions of specific organic compounds in each size particle bin were identified in this study, implying that innovative analytical technology such as real-time measurements of particle-associated organic compounds using a thermal desorption-aerosol gas chromatography approach should be urgently developed.

Data availability. The data used for this study can be obtained from fzhangtj@tongji.edu.cn upon request.
Supplement. The supplement related to this article is available online at: https://doi.org/10.5194/acp-20-1549-2020-supplement.

Author contributions. FZ did the sampling and led the writing and data analysis for the paper, with significant contributions and comments from all co-authors. YC designed the field measurements, and HG reviewed and edited the paper. VM, YZ, XY and JC contributed to the data analysis, the paper structure and the writing of the text.

Competing interests. The authors declare that they have no conflict of interest.

Special issue statement. This article is part of the special issue "Shipping and the Environment - From Regional to Global Perspectives (ACP/OS inter-journal SI)". It is a result of the Shipping and the Environment - From Regional to Global Perspectives, Gothenburg, Sweden, 23-24 October 2017.

Acknowledgements. The authors wish to thank Min Cui, Yong Han, Zhe Qian and Yajing $\mathrm{Lu}$ for the help with experimental work. This study was financially supported by the Research Grants Council of the Hong Kong Special Administrative Region (SAR) via the Theme-based Research Scheme (TRS; project T24504/17-N), the Natural Science Foundation of China (grant nos. 41761134083, 91744203, 41603090 and 21677038), the National Research Program for Key Issues in Air Pollution Control (grant no. DQGG0201), the Collaborative Research program between the Beijing University of Technology and the Hong Kong Polytechnic University (grant no. 4-ZZFW), and the Hong Kong PolyU internal grants (grant nos. 1-ZVJT and 1-BBW4).

Financial support. This research has been supported by the Research Grants Council of the Hong Kong Special Administrative Region (SAR) via the Theme-based Research Scheme (TRS; project T24-504/17-N), the Natural Science Foundation of China (grant nos. 41761134083, 91744203, 41603090 and 21677038), the National Research Program for Key Issues in Air Pollution Control (grant no. DQGG0201), the Collaborative Research program between the Beijing University of Technology and the Hong Kong Polytechnic University (grant no. 4-ZZFW), and the Hong Kong PolyU internal grants (grant nos. 1-ZVJT and 1-BBW4).

Review statement. This paper was edited by Jana Moldanová and reviewed by two anonymous referees.

\section{References}

Agrawal, H., Malloy, Q. G. J., Welch, W. A., Miller, J. W., and Cocker, D. R., III: In-use gaseous and particulate matter emissions from a modern ocean go- 
ing container vessel, Atmos. Environ., 42, 5504-5510, https://doi.org/10.1016/j.atmosenv.2008.02.053, 2008.

Agrawal, H., Eden, R., Zhang, X., Fine, P. M., Katzenstein, A., Miller, J. W., Ospital, J., Teffera, S., and Cocker III, D. R.: Primary Particulate Matter from Ocean-Going Engines in the Southern California Air Basin, Environ. Sci. Technol., 43, 5398-5402, https://doi.org/10.1021/es8035016, 2009.

Agrawal, H., Welch, W. A., Henningsen, S., Miller, J. W., and Cocker, D. R.: Emissions from main propulsion engine on container ship at sea, J. Geophys. Res.-Atmos., 115, D23205, https://doi.org/10.1029/2009jd013346, 2010.

Alföldy, B., Lööv, J. B., Lagler, F., Mellqvist, J., Berg, N., Beecken, J., Weststrate, H., Duyzer, J., Bencs, L., Horemans, B., Cavalli, F., Putaud, J.-P., Janssens-Maenhout, G., Csordás, A. P., Van Grieken, R., Borowiak, A., and Hjorth, J.: Measurements of air pollution emission factors for marine transportation in SECA, Atmos. Meas. Tech., 6, 1777-1791, https://doi.org/10.5194/amt6-1777-2013, 2013.

Alves, C. A., Barbosa, C., Rocha, S., Calvo, A., Nunes, T., Cerqueira, M., Pio, C., Karanasiou, A., and Querol, X.: Elements and polycyclic aromatic hydrocarbons in exhaust particles emitted by light-duty vehicles, Environ. Sci. Pollut. Res., 22, 1152611542, https://doi.org/10.1007/s11356-015-4394-x, 2015.

Beecken, J., Mellqvist, J., Salo, K., Ekholm, J., and Jalkanen, J.P.: Airborne emission measurements of $\mathrm{SO}_{2}, \mathrm{NO}_{x}$ and particles from individual ships using a sniffer technique, Atmos. Meas. Tech., 7, 1957-1968, https://doi.org/10.5194/amt-7-1957-2014, 2014.

Cappa, C. D., Williams, E. J., Lack, D. A., Buffaloe, G. M., Coffman, D., Hayden, K. L., Herndon, S. C., Lerner, B. M., Li, S.-M., Massoli, P., McLaren, R., Nuaaman, I., Onasch, T. B., and Quinn, P. K.: A case study into the measurement of ship emissions from plume intercepts of the NOAA ship Miller Freeman, Atmos. Chem. Phys., 14, 1337-1352, https://doi.org/10.5194/acp14-1337-2014, 2014.

Chu-Van, T., Ristovski, Z., Pourkhesalian, A. M., Rainey, T., Garaniya, V., Abbassi, R., Jahangiri, S., Enshaei, H., Kam, U. S., Kimball, R., Yang, L., Zare, A., Bartlett, H., and Brown, R. J.: On-board measurements of particle and gaseous emissions from a large cargo vessel at different operating conditions, Environ. Pollut., 237, 832-841, https://doi.org/10.1016/j.envpol.2017.11.008, 2017.

Cooper, D. A.: Exhaust emissions from ships at berth, Atmos. Environ., 37, 3817-3830, https://doi.org/10.1016/s13522310(03)00446-1, 2003.

Corbett, J. J., Lack, D. A., Winebrake, J. J., Harder, S., Silberman, J. A., and Gold, M.: Arctic shipping emissions inventories and future scenarios, Atmos. Chem. Phys., 10, 9689-9704, https://doi.org/10.5194/acp-10-9689-2010, 2010.

Diesch, J.-M., Drewnick, F., Klimach, T., and Borrmann, S.: Investigation of gaseous and particulate emissions from various marine vessel types measured on the banks of the Elbe in Northern Germany, Atmos. Chem. Phys., 13, 3603-3618, https://doi.org/10.5194/acp-13-3603-2013, 2013.

Fridell, E., Steen, E., and Peterson, K.: Primary particles in ship emissions, Atmos. Environ., 42, 1160-1168, 2008.

Gregoris, E., Barbaro, E., Morabito, E., Toscano, G., Donateo, A., Cesari, D., Contini, D., and Gambaro, A.: Impact of maritime traffic on polycyclic aromatic hydrocarbons, metals and partic- ulate matter in Venice air, Environ. Sci. Pollut. Res., 23, 69516959, https://doi.org/10.1007/s11356-015-5811-x, 2016.

Han, Y., Chen, Y. J., Ahmad, S., Feng, Y. L., Zhang, F., Song, W. H., Cao, F., Zhang, Y. L., Yang, X., Li, J., and Zhang, G.: High Time- and Size-Resolved Measurements of PM and Chemical Composition from Coal Combustion: Implications for the EC Formation Process, Environ. Sci. Technol., 52, 6676-6685, https://doi.org/10.1021/acs.est.7b05786, 2018.

Hardy, W. L. and Reitz, R. D.: A Study of the Effects of High EGR, High Equivalence Ratio, and Mixing Time on Emissions Levels in a Heavy-Duty Diesel Engine for PCCI Combustion, SAE International, 2006.

Healy, R. M., O’Connor, I. P., Hellebust, S., Allanic, A., Sodeau, J. R., and Wenger, J. C.: Characterisation of single particles from in-port ship emissions, Atmos. Environ., 43, 6408-6414, https://doi.org/10.1016/j.atmosenv.2009.07.039, 2009.

Heywood, J. B.: Internal combustion engine fundamentals, Mcgraw-hill New York, 1988.

Hobbs, P. V., Garrett, T. J., Ferek, R. J., Strader, S. R., Hegg, D. A., Frick, G. M., Hoppel, W. A., Gasparovic, R. F., Russell, L. M., Johnson, D. W., O’Dowd, C., Durkee, P. A., Nielsen, K. E., and Innis, G.: Emissions from ships with respect to their effects on clouds, J. Atmos. Sci., 57, 2570-2590, https://doi.org/10.1175/1520-0469(2000)057< 2570:efswrt>2.0.co;2, 2000.

Juwono, A. M., Johnson, G., Mazaheri, M., Morawska, L., Roux, F., and Kitchen, B.: Investigation of the airborne submicrometer particles emitted by dredging vessels using a plume capture method, Atmos. Environ., 73, 112-123, 2013.

Kasper, A., Aufdenblatten, S., Forss, A., Mohr, M., and Burtscher, H.: Particulate Emissions from a Low-Speed Marine Diesel Engine, Aerosol Sci. Technol., 41, 24-32, https://doi.org/10.1080/02786820601055392, 2007.

Kittelson, D. B.: Engines and nanoparticles: a review, J. Aerosol. Sci., 29, 575-588, https://doi.org/10.1016/S00218502(97)10037-4, 1998.

Lighty, J. S., Veranth, J. M., and Sarofim, A. F.: Combustion aerosols: Factors governing their size and composition and implications to human health, J. Air Waste Manage. Assoc., 50, 15651618, https://doi.org/10.1080/10473289.2000.10464197, 2000.

Liu, H., Fu, M., Jin, X., Shang, Y., Shindell, D., Faluvegi, G., Shindell, C., and He, K.: Health and climate impacts of oceangoing vessels in East Asia, Nat. Clim. Chang., 6, 1037-1041, https://doi.org/10.1038/nclimate3083, 2016.

Liu, Z., Lu, X., Feng, J., Fan, Q., Zhang, Y., and Yang, X.: Influence of Ship Emissions on Urban Air Quality: A Comprehensive Study Using Highly Time-Resolved Online Measurements and Numerical Simulation in Shanghai, Environ. Sci. Technol., 51, 202-211, https://doi.org/10.1021/acs.est.6b03834, 2017.

Lombaert, K., Le Moyne, L., De Maleissye, J. T., and Amouroux, J.: Experimental study of PAH in engine soot by isotopic tracing, Combust. Sci. Technol., 178, 707-728, https://doi.org/10.1080/0010220500248417, 2006.

Lu, G., Brook, J. R., Alfarra, M. R., Anlauf, K., Leaitch, W. R., Sharma, S., Wang, D., Worsnop, D. R., and Phinney, L.: Identification and characterization of inland ship plumes over Vancouver, BC, Atmos. Environ., 40, 2767-2782, https://doi.org/10.1016/j.atmosenv.2005.12.054, 2006. 
Moldanová, J., Fridell, E., Popovicheva, O., Demirdjian, B., Tishkova, V., Faccinetto, A., and Focsa, C.: Characterisation of particulate matter and gaseous emissions from a large ship diesel engine, Atmos. Environ., 43, 2632-2641, https://doi.org/10.1016/j.atmosenv.2009.02.008, 2009.

Moldanová, J., Fridell, E., Winnes, H., Holmin-Fridell, S., Boman, J., Jedynska, A., Tishkova, V., Demirdjian, B., Joulie, S., Bladt, H., Ivleva, N. P., and Niessner, R.: Physical and chemical characterisation of PM emissions from two ships operating in European Emission Control Areas, Atmos. Meas. Tech., 6, 35773596, https://doi.org/10.5194/amt-6-3577-2013, 2013.

Murphy, S. M., Agrawal, H., Sorooshian, A., Padró, L. T., Gates, H., Hersey, S., Welch, W., Jung, H., Miller, J., and Cocker III, D. R.: Comprehensive simultaneous shipboard and airborne characterization of exhaust from a modern container ship at sea, Environ. Sci. Technol., 43, 4626-4640, 2009.

Oeder, S., Kanashova, T., Sippula, O., Sapcariu, S. C., Streibel, T., Arteaga-Salas, J. M., Passig, J., Dilger, M., Paur, H.-R., Schlager, C., Mulhopt, S., Diabate, S., Weiss, C., Stengel, B., Rabe, R., Harndorf, H., Torvela, T., Jokiniemi, J. K., Hirvonen, M.-R., Schmidt-Weber, C., Traidl-Hoffmann, C., Berube, K. A., Wlodarczyk, A. J., Prytherch, Z., Michalke, B., Krebs, T., Prevot, A. S. H., Kelbg, M., Tiggesbaumker, J., Karg, E., Jakobi, G., Scholtes, S., Schnelle-Kreis, J., Lintelmann, J., Matuschek, G., Sklorz, M., Klingbeil, S., Orasche, J., Richthammer, P., Muller, L., Elsasser, M., Reda, A., Groger, T., Weggler, B., Schwemer, T., Czech, H., Ruger, C. P., Abbaszade, G., Radischat, C., Hiller, K., Buters, J. T. M., Dittmar, G., and Zimmermann, R.: Particulate Matter from Both Heavy Fuel Oil and Diesel Fuel Shipping Emissions Show Strong Biological Effects on Human Lung Cells at Realistic and Comparable In Vitro Exposure Conditions, PLoS One, 10, e0126536, https://doi.org/10.1371/journal.pone.0126536, 2015.

Pandolfi, M., Gonzalez-Castanedo, Y., Alastuey, A., de la Rosa, J. D., Mantilla, E., Sanchez de la Campa, A., Querol, X., Pey, J., Amato, F., and Moreno, T.: Source apportionment of $\mathrm{PM}_{10}$ and $\mathrm{PM}_{2.5}$ at multiple sites in the strait of Gibraltar by PMF: impact of shipping emissions, Environ. Sci. Pollut. Res., 18, 260-269, https://doi.org/10.1007/s11356-010-0373-4, 2011.

Pergal, M. M., Tesic, Z. L., and Popovic, A. R.: Polycyclic Aromatic Hydrocarbons: Temperature Driven Formation and Behavior during Coal Combustion in a Coal-Fired Power Plant, Energy Fuels, 27, 6273-6278, https://doi.org/10.1021/ef401467z, 2013.

Petzold, A., Hasselbach, J., Lauer, P., Baumann, R., Franke, K., Gurk, C., Schlager, H., and Weingartner, E.: Experimental studies on particle emissions from cruising ship, their characteristic properties, transformation and atmospheric lifetime in the marine boundary layer, Atmos. Chem. Phys., 8, 2387-2403, https://doi.org/10.5194/acp-8-2387-2008, 2008.

Pongpiachan, S., Hattayanone, M., Choochuay, C., Mekmok, R., Wuttijak, N., and Ketratanakul, A.: Enhanced $\mathrm{PM}_{10}$ bounded PAHs from shipping emissions, Atmos. Environ., 108, 13-19, https://doi.org/10.1016/j.atmosenv.2015.02.072, 2015.

Quinn, P. K., Stohl, A., Arneth, A., Berntsen, T., Burkhart, J. F., Christensen, J., Flanner, M., Kupiainen, K., Lihavainen, H., and Shepherd, M.: The Impact of Black Carbon on Arctic Climate, Arctic Monitoring and Assessment Programme, 2011.

Robinson, A. L., Grieshop, A. P., Donahue, N. M., and Hunt, S. W.: Updating the conceptual model for fine particle mass emis- sions from combustion systems Allen L. Robinson, J. Air Waste Manage. Assoc., 60, 1204-1222, 2010.

Schröder, C., Reimer, N., and Jochmann, P.: Environmental impact of exhaust emissions by Arctic shipping, Ambio, 46, 400-409, https://doi.org/10.1007/s13280-017-0956-0, 2017.

Shen, G., Wang, W., Yang, Y., Zhu, C., Min, Y., Xue, M., Ding, J., Li, W., Wang, B., Shen, H., Wang, R., Wang, X., and Tao, S.: Emission factors and particulate matter size distribution of polycyclic aromatic hydrocarbons from residential coal combustions in rural Northern China, Atmos. Environ., 44, 5237-5243, https://doi.org/10.1016/j.atmosenv.2010.08.042, 2010.

Shen, G., Wang, W., Yang, Y., Ding, J., Xue, M., Min, Y., Zhu, C., Shen, H., Li, W., Wang, B., Wang, R., Wang, X., Tao, S., and Russell, A. G.: Emissions of PAHs from Indoor Crop Residue Burning in a Typical Rural Stove: Emission Factors, Size Distributions, and Gas-Particle Partitioning, Environ. Sci. Technol., 45, 1206-1212, https://doi.org/10.1021/es102151w, 2011.

Sinha, P., Hobbs, P. V., Yokelson, R. J., Christian, T. J., Kirchstetter, T. W., and Bruintjes, R.: Emissions of trace gases and particles from two ships in the southern Atlantic Ocean, Atmos. Environ., 37, 2139-2148, https://doi.org/10.1016/s13522310(03)00080-3, 2003.

Sippula, O., Stengel, B., Sklorz, M., Streibel, T., Rabe, R., Orasche, J., Lintelmann, J., Michalke, B., Abbaszade, G., Radischat, C., Groeger, T., Schnelle-Kreis, J., Harndorf, H., and Zimmermann, R.: Particle Emissions from a Marine Engine: Chemical Composition and Aromatic Emission Profiles under Various Operating Conditions, Environ. Sci. Technol., 48, 11721-11729, https://doi.org/10.1021/es502484z, 2014.

Tree, D. R. and Svensson, K. I.: Soot processes in compression ignition engines, Prog. Energy Combust. Sci., 33, 272-309, https://doi.org/10.1016/j.pecs.2006.03.002, 2007.

Viana, M., Hammingh, P., Colette, A., Querol, X., Degraeuwe, B., de Vlieger, I., and van Aardenne, J.: Impact of maritime transport emissions on coastal air quality in Europe, Atmos. Environ., 90, 96-105, https://doi.org/10.1016/j.atmosenv.2014.03.046, 2014.

Vieira de Souza, C. and Corrêa, S. M.: Polycyclic aromatic hydrocarbon emissions in diesel exhaust using gas chromatographymass spectrometry with programmed temperature vaporization and large volume injection, Atmos. Environ., 103, 222-230, https://doi.org/10.1016/j.atmosenv.2014.12.047, 2015.

Winnes, H. and Fridell, E.: Emissions of $\mathrm{NO}_{x}$ and particles from manoeuvring ships, Transport Res. D-Tr. E., 15, 204-211, https://doi.org/10.1016/j.trd.2010.02.003, 2010.

Wu, D., Li, Q., Ding, X., Sun, J., Li, D., Fu, H., Teich, M., Ye, X., and Chen, J.: Primary Particulate Matter Emitted from Heavy Fuel and Diesel Oil Combustion in a Typical Container Ship: Characteristics and Toxicity, Environ. Sci. Technol., 52, 1294312951, https://doi.org/10.1021/acs.est.8b04471, 2018.

Yang, H.-H., Chien, S.-M., Chao, M.-R., and Wang, Y.-F.: Size Distribution of Particulate Polycyclic Aromatic Hydrocarbons in the Diluted Four-stroke Motorcycle Exhausts, Aerosol Air Qual. Res., 5, 225-235, https://doi.org/10.4209/aaqr.2005.12.0008, 2005.

Zetterdahl, M.: Particle Emissions from Ships, Thesis, Chalmers University of Technoilogy, Gothenbur, Sweden, 2016.

Zetterdahl, M., Salo, K., Fridell, E., and Sjoblom, J.: Impact of Aromatic Concentration in Marine Fuels on Par- 
ticle Emissions, Aerosol Air Qual. Res., 16, 352-361, https://doi.org/10.1007/s11804-017-1417-7, 2017.

Zhang, F., Chen, Y., Tian, C., Lou, D., Li, J., Zhang, G., and Matthias, V.: Emission factors for gaseous and particulate pollutants from offshore diesel engine vessels in China, Atmos. Chem. Phys., 16, 6319-6334, https://doi.org/10.5194/acp-166319-2016, 2016.

Zhang, F., Chen, Y., Chen, Q., Feng, Y., Shang, Y., Yang, X., Gao, H., Tian, C., Li, J., Zhang, G., Matthias, V., and Xie, Z.: Real-World Emission Factors of Gaseous and Particulate Pollutants from Marine Fishing Boats and Their Total Emissions in China, Environ. Sci. Technol., 52, 4910-4919, https://doi.org/10.1021/acs.est.7b04002, 2018.
Zhang, F., Chen, Y., Cui, M., Feng, Y., Yang, X., Chen, J., Zhang, Y., Gao, H., Tian, C., Matthias, V., and Liu, H.: Emission factors and environmental implication of organic pollutants in PM emitted from various vessels in China, Atmos. Environ., 200, 302-311, https://doi.org/10.1016/j.atmosenv.2018.12.006, 2019.

Zhao, M., Zhang, Y., Ma, W., Fu, Q., Yang, X., Li, C., Zhou, B., Yu, Q., and Chen, L.: Characteristics and ship traffic source identification of air pollutants in China's largest port, Atmos. Environ., 64, 277-286, https://doi.org/10.1016/j.atmosenv.2012.10.007, 2013. 